\title{
A combined laser flash photolysis, density functional theory and atoms in molecules study of the photochemical hydrogen abstraction by pyrene-4,5-dione
}

\author{
Nanci C. de Lucas ${ }^{a}, *$, Mônica M. Elias ${ }^{a}$, Caio L. Firme ${ }^{a}$, Rodrigo J. Corrêa ${ }^{a}$, Simon J. Garden ${ }^{\text {, }}$ \\ José Carlos Netto-Ferreira ${ }^{\mathrm{b}}$, David E. Nicodem ${ }^{\mathrm{a}}$ \\ a Instituto de Química - Universidade Federal do Rio de Janeiro, Avenida Athos da Silveira Ramos, 149, CT, Bloco A, 21941-909 Cidade Universitária, RJ, Brazil

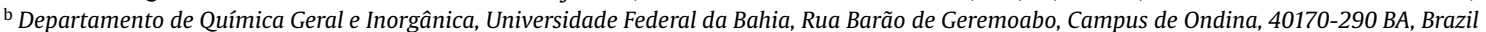

\section{A R T I C L E I N F O}

\section{Article history:}

Received 11 June 2008

Received in revised form 15 August 2008

Accepted 20 August 2008

Available online 3 September 2008

\section{Keywords:}

Laser flash photolysis

Ortho-quinone

Triplet excited state

DFT

Hydrogen atom transfer

\begin{abstract}
A B S T R A C T
The photochemical hydrogen abstraction reaction of pyrene-4,5-dione (3) has been investigated by laser flash photolysis. Excitation $(\lambda=355 \mathrm{~nm}$ ) of a degassed solution of $\mathbf{3}$ in acetonitrile resulted in the formation of a detectable transient with absorption maxima at 380 and $470 \mathrm{~nm}$. This transient decays with a lifetime of around $4.8 \mu \mathrm{s}$ and is quenched by oxygen. This transient is most probably a triplet state of 3 . Addition of hydrogen donors, such as 2-propanol; 1,4-cyclohexadiene or 4-methoxyphenol led to the formation of a new transient with $\lambda_{\max }$ at $380,500 \mathrm{~nm}$ and a broad absorption at $640 \mathrm{~nm}$. This new transient slowly decays with second order kinetics and was assigned to the semiquinone radical obtained from the hydrogen abstraction reaction. Using DFT and AIM calculations the reactivity of 3 and 9,10-phenanthrenequinone (1) is best interpreted as a proton coupled electron transfer like mechanism for the hydrogen abstraction from 2-propanol.
\end{abstract}

(C) 2008 Elsevier B.V. All rights reserved.

\section{Introduction}

It is known that ortho-quinones play important roles in photobiology [1-5]. The photochemistry of $\alpha$-diketones (and the closely related ortho-quinones) has been a subject of interest for a long time and this field of investigation has continued to be very active [6]. Several ortho-quinones have been found to be photoreactive in the presence of hydrogen and electron donors [7-24].

The reactivity of aromatic ketones is dependent on the nature of their lowest triplet excited state, with the $n, \pi^{*}$ triplet being the reactive state [25]. Where the ketones have a lowest $\pi, \pi^{*}$ triplet state it has been accepted that they react predominantly via the higher energy $n, \pi^{*}$ state, populated thermally from the lower energy state $[20,26,27]$. The photoreactivity of 9,10-phenanthrenequinone (1) and other triplets $[17,20]$ has been observed to be dependent upon the solvent polarity and is related to a small energy separation between the $n, \pi^{*}$ and $\pi, \pi^{*}$ triplet levels, thus leading to an inversion of the configuration. On the other hand, quinone $\mathbf{2}$ does not show an inversion of the triplet state, and is found to be $\pi, \pi^{*}$ in all solvents. As a result, 2 is less reactive than 1 towards hydrogen abstraction [17,19].

\footnotetext{
* Corresponding author. Tel.: +55 212562 7278; fax: +55 2125627106

E-mail address: nancicl@iq.ufrj.br (N.C. de Lucas).
}

The irradiation of ortho-quinones in the presence of olefins leads to the formation of dihydrodioxins (DHDs) [6-8,12,28-30]. These adducts have been used as a photoactivated masking group for DNA cleavage [31]. Recently, Wilson and coworkers showed that for pyrene-4,5-dione dihydrodioxins the reaction is reversible with UV light, releasing pyrene-4,5-dione (3) [32].

This study reports the first results of the photochemical hydrogen abstraction reaction of $\mathbf{3}$ as investigated by laser flash photolysis irradiation. In addition, DFT and AIM calculations of the reactions of the triplet excited states of $\mathbf{1}$ and $\mathbf{3}$ with 2-propanol were performed.

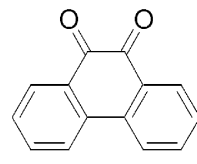

1<smiles>O=c1c(=O)c2c3c4ccccc4cc-3cccc12</smiles>

2

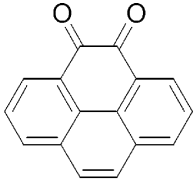

3

\section{Materials and methods}

\subsection{Materials}

Solvents were UV grade. Pyrene-4,5-dione (3) was prepared according to a literature procedure and spectroscopic data were in 
accord with the reported results [33]. The quinone was recrystallized from acetonitrile from which crystals suitable for single crystal $\mathrm{X}$-ray diffraction were obtained. Initial diffraction studies revealed an identical crystal system, space group and unit cell dimensions similar to those reported by Müellen [34]. 4-Methoxyphenol, 1,4cyclohexadiene and $\beta$-carotene (Aldrich), were used as received.

\subsection{Laser flash photolysis}

The laser flash photolysis experiments were carried out on a LuzChem Instrument model mLFP122 either at the University of Ottawa, Canada, or at the Universidade Federal da Bahia, Brazil. Samples were contained in a $10 \mathrm{~mm} \times 10 \mathrm{~mm}$ cell made from Suprasil tubing and were deaerated by bubbling with oxygenfree nitrogen for about $30 \mathrm{~min}$. The samples were irradiated with a Nd/YAG Surelite laser, using the third harmonic $(\lambda=355 \mathrm{~nm}$, $\sim 4-6 \mathrm{~ns}, \geq 40 \mathrm{~mJ} /$ pulse), with the signal being detected by a Tektronix TDS2012 oscilloscope. The concentration of $\mathbf{3}(\sim 1 \mathrm{mM})$ was chosen in order to give an absorption at the wavelength of excitation (355 $\mathrm{nm}$ ) of $\sim 0.5$.

\subsection{Low temperature phosphoresce}

The phosphorescence spectra in methylcyclohexane glass of $\mathbf{3}$ were recorded on a Time Resolved fluorometer from Edinburgh Analytical Instrument F900 in the phosphorescence mode which used a Xe pulsed lamp and a multichanel scaler.

\subsection{Computational methods}

The geometries were optimized using standard techniques [35], and after geometry optimization, vibrational analysis was performed and the resulting geometries were confirmed as true minima on the potential energy surface, as shown by the absence of imaginary frequencies. Geometrical, energetic and AIM calculations were performed at UB3LYP/6-311++G**//UB3LYP/6-31G* for all structures. Energy differences correspond to enthalpy differences at $298 \mathrm{~K}$ and $1 \mathrm{~atm}$. All calculations were performed with the Gaussian 98 package of programs [36]. AIM (atoms in molecules) $[37,38]$ calculations were performed on AIM 2000, v2.0. The AIM theory was used to investigate the interactions involved in the hydrogen abstraction reaction from the triplet state of $\mathbf{1}$ and $\mathbf{3}$.

\section{Results and discussion}

\subsection{Laser flash photolysis}

Laser irradiation of a deoxygenated solution of $\mathbf{3}$ in acetonitrile resulted in the formation of a signal with maximum at 380 and $470 \mathrm{~nm}$ (Fig. 1). This transient decays by first order kinetics with a lifetime of around $4.8 \mu \mathrm{s}$ and was quenched by oxygen (see insert Fig. 1). This decay is concentration dependent, reflecting selfquenching of the triplet. For acetonitrile we were able to measure a self-quenching rate constant of $3.1 \times 10^{8} \mathrm{~L} \mathrm{~mol}^{-1} \mathrm{~s}^{-1}$. A similar value $\left(2.0 \times 10^{8} \mathrm{~L} \mathrm{~mol}^{-1} \mathrm{~s}^{-1}\right)$ was found for the triplet of 9,10 phenanthrenequinone (1) in the same solvent [20]. The transient from irradiation of 3 is quenched by $\beta$-carotene $\left(E_{\mathrm{T}}=21 \mathrm{kcal} \mathrm{mol}^{-1}\right)$ [39] with a diffusion controlled rate constant, leading to the formation of a $520 \mathrm{~nm}$ band characteristic of the $\beta$-carotene triplet.

Addition of 2-propanol, 1,4-cyclohexadiene or 4methoxyphenol led to a shortening of the triplet lifetime of 3. The triplet decay of this ketone followed pseudo-first-order kinetics in the presence of these quenchers, with the experimentally observed kinetic rate constant, $k_{\text {obs }}$, being related to the

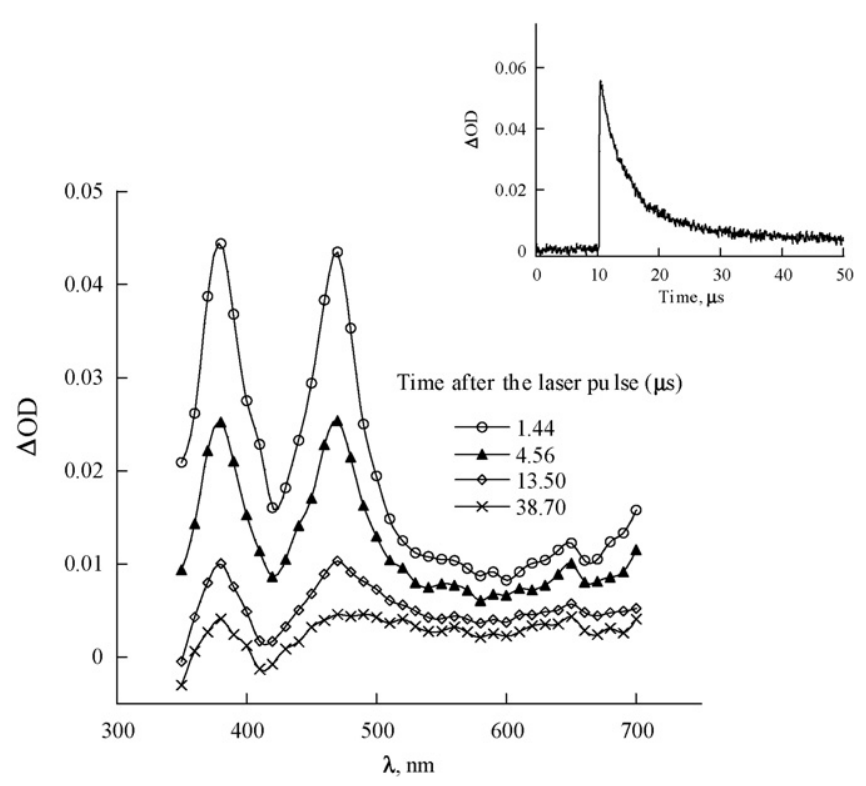

Fig. 1. Transient absorption spectra recorded after $355 \mathrm{~nm}$ laser excitation of $\mathbf{3}$ in acetonitrile solution. Insert: decay at $470 \mathrm{~nm}$.

quenching rate constant, $k_{\mathrm{q}}$, according to Eq. (1):

$k_{\mathrm{obs}}=k_{0}+k_{\mathrm{q}}[Q]$

where $k_{0}$ is the decay rate constant of the triplet in the absence of the quencher, and $[Q]$ is the quencher concentration. Plots based on this equation for the triplet of $\mathbf{3}$ being quenched by 2-propanol, 1,4-cyclohexadiene or 4-methoxyphenol were found to be linear, from which the value of $k_{\mathrm{q}}$ can be determined. Fig. 2 shows a representative quenching plot for 2-propanol and Table 1 details the rate constants.

The addition of 2-propanol to an acetonitrile solution of 3 leads to the formation of a new transient with $\lambda_{\max }$ around 380 and $500 \mathrm{~nm}$ and a broad absorption at $640 \mathrm{~nm}$. Fig. 3 shows the transient absorption spectra recorded in neat 2-propanol. These spectra also show a strong bleaching signal centered at $415 \mathrm{~nm}$, which is coincident with the maximum absorption for $\mathbf{3}$ in the ground-state. It is important to note that the triplet absorption spectrum for $\mathbf{3}$ in acetonitrile also shows a valley in the same region. Similar

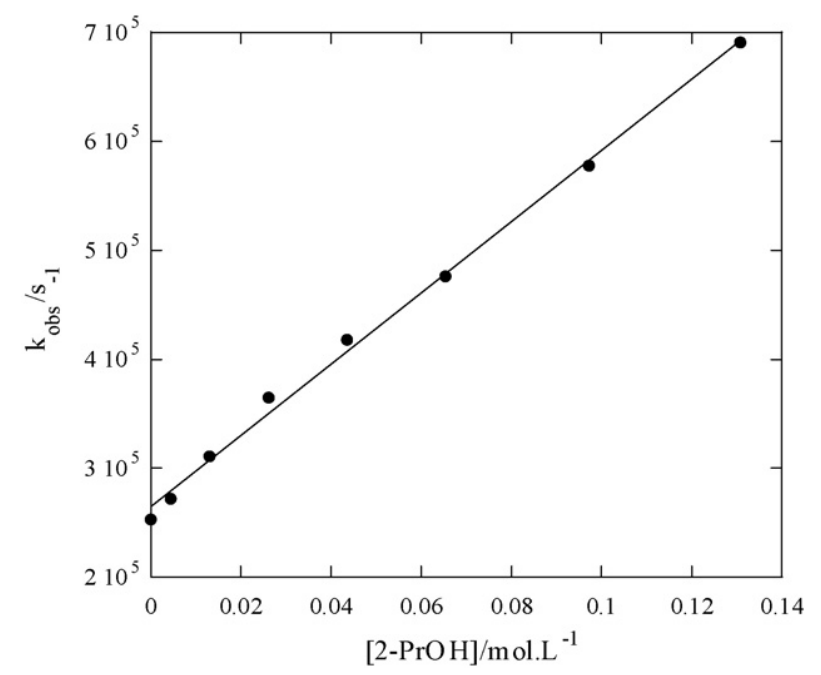

Fig. 2. Quenching plot for the triplet of 3 by 2-propanol in acetonitrile solution. $\lambda_{\text {exc }}=355 \mathrm{~nm} ; \lambda_{\text {mon }}=470 \mathrm{~nm}$. 
Table 1

Second-order rate constants for the quenching of the triplet excited state of $\mathbf{3}$ in acetonitrile

\begin{tabular}{ll}
\hline Quencher & $k_{\mathrm{q}}\left(\mathrm{L} \mathrm{mol}^{-1} \mathrm{~s}^{-1}\right)^{\mathrm{a}}$ \\
\hline 2-Propanol & $3.3 \times 10^{6}$ \\
2-Propanol & $5.8 \times 10^{8 \mathrm{~b}}$ \\
1,4-Cyclohexadiene & $3.7 \times 10^{7}$ \\
4-Methoxyphenol & $3.4 \times 10^{9}$
\end{tabular}

a Estimated to be accurate to $\pm 10 \% ; \lambda_{\text {mon }}=470 \mathrm{~nm}$.

b In chlorobenzene.

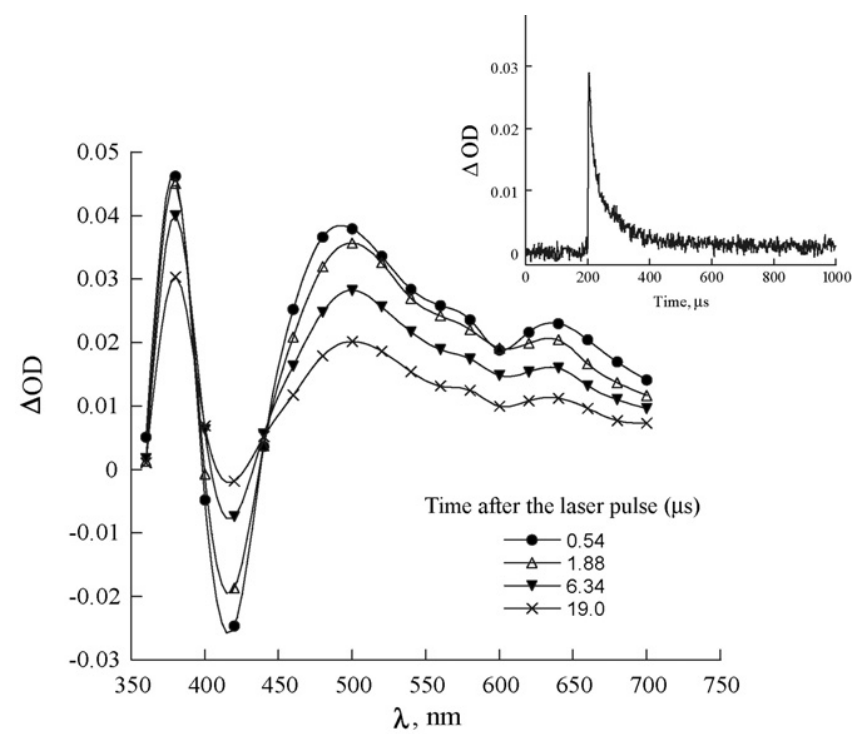

Fig. 3. Transient absorption spectra recorded after $355 \mathrm{~nm}$ laser excitation of $\mathbf{3}$ in 2-propanol solution. Insert: decay at $470 \mathrm{~nm}$.

transient spectra were also observed in neat methanol and with 1,4-cyclohexadiene $\left(8 \times 10^{-3} \mathrm{~mol} \mathrm{~L}^{-1}\right)$ in acetonitrile solution. This new transient slowly decays with second order kinetics and could be assigned to the semiquinone radical obtained from the hydrogen abstraction reaction for the triplet of $\mathbf{3}$ with $\mathrm{H}$-donors (Fig. 3, insert). Similarly, triplet phenanthrenequinone (1) reacts with 2-propanol generating its corresponding semiquinone radical with maximum absorption at $380 \mathrm{~nm}[8,21]$.

Table 1 also shows the reactivity of the triplet of $\mathbf{3}$ with 2propanol in chlorobenzene $(\mathrm{CB})$ as solvent. The reactivity of $\mathbf{3}$ in this solvent is two orders of magnitude greater than in acetonitrile. In the case of $\mathbf{1}$, reaction in these solvents was found to result in a difference of one order of magnitude in the reaction rate constants $\left(k_{\mathrm{q}}^{\mathrm{ACN}}=2.5 \times 10^{7}\right.$ and $\left.k_{\mathrm{q}}^{\mathrm{CB}}=1.2 \times 10^{8} \mathrm{~L} \mathrm{~mol}^{-1} \mathrm{~s}^{-1}\right)$ [20]. Here, 3 is found to be approximately five times as reactive as $\mathbf{1}$ in chlorobenzene but $\mathbf{1}$ is eight times more reactive than $\mathbf{3}$ in acetonitrile. The effect of increasing the photoreactivity with a decrease in solvent polarity is not unprecedent $[17,18,40,41]$, and has been interpreted as being due to a small energy separation between the $n, \pi^{*}$ and $\pi, \pi^{*}$ triplet levels. Indeed, the change in solvent polarity can lead to an inversion of the triplet levels for the quinone triplet $\mathbf{1}[17,18]$. Similar behavior is observed for $\mathbf{3}$, where the larger difference between $k_{\mathrm{q}}$ in acetonitrile and chlorobenzene, in comparison with $\mathbf{1}$, is probably due to a larger energy difference between $n, \pi^{*}$ and $\pi, \pi^{*}$ excited states for $\mathbf{3}$ in the non-polar medium.

\subsection{Theoretical calculations}

Recently we employed DFT calculations to probe the reaction mechanism of different ortho-quinone triplets with phenol [23]. DFT calculations have also been used to understand an analogous mechanism, the photoreduction of 2-benzoylthiophene by phenol $[42,43]$, as well as the macrocyclization of ketoprofen through an intramolecular hydrogen abstraction reaction [44]. In addition, Pan et al. have used DFT calculations to investigate the photoreduction of ortho-naphthoquinones where they found that the ionization/electron affinity and redox potentials of the quinones resulted in a good correlation with experimental Hammett values [22].

In the present study the reaction mechanism for the triplets $\mathbf{1}$ and 3 with 2-propanol was theoretically studied using DFT methods. The calculations were performed to evaluate the degree of electron transfer in the hydrogen abstraction reaction from 2propanol. All the computed geometries were performed without solvent effects. Hydrogen abstraction from 2-propanol (2-PrOH) by the triplet ketone, yielding the triplet radical pair, was rationalized in a three step mechanism. Firstly, ground state $S_{0}$ complexes (ketone/2-propanol) involving a carbonyl oxygen interaction with the hydrogen-oxygen bond $\left(\mathrm{S}_{0} \mathrm{C}=\mathrm{O}-\mathrm{H}-\mathrm{O}\right)$ and a complex involving a carbonyl oxygen interaction with the secondary hydrogen-carbon bond $\left(\mathrm{S}_{0} \mathrm{C}=\mathrm{O}-\mathrm{H}-\mathrm{C}\right)$ of the hydrogen donor were located. The free energy difference $\left(\Delta \Delta G_{298}\right)$ between the two $S_{0}$ complexes ( $\mathrm{C}=\mathrm{O}-\mathrm{H}-\mathrm{C}$ and $\mathrm{C}=\mathrm{O}-\mathrm{H}-\mathrm{O}$ ) was 3.5 and $2.9 \mathrm{kcal} / \mathrm{mol}$ for $\mathbf{1}$ and $\mathbf{3}$, respectively. Secondly, the $\mathrm{S}_{0} \mathrm{C}=\mathrm{O}-\mathrm{H}-\mathrm{C}$ complexes were used as starting points to try to locate a triplet quinone/2-PrOH complex involving the secondary $\mathrm{C}-\mathrm{H}-\mathrm{O}=\mathrm{C}$ interaction. The reasons for this choice were: (a) due to the fact that hydrogen abstraction occurs exclusively from the secondary $\mathrm{C}-\mathrm{H}$ bond and (b) that despite the $\mathrm{S}_{0}$ $\mathrm{C}=\mathrm{O}-\mathrm{H}-\mathrm{O}$ complex being lower in energy, a triplet complex involving a $\mathrm{C}=\mathrm{O}-\mathrm{H}-\mathrm{O}$ interaction should be chemically unfavourable due to the electrophilic nature of the quinone $\mathrm{T}_{1}$ state. However, we were unable to optimize a triplet $\mathrm{C}=\mathrm{O}-\mathrm{H}-\mathrm{C}$ complex and all attempts to localize such a complex resulted in the formation of the triplet radical pair. On the other hand, the subsequent steps, i.e. the triplet transition state for hydrogen abstraction and the triplet radical pair product were fully optimized. Fig. 4 depicts the structures computed for the $\mathrm{S}_{0} \mathrm{C}=\mathrm{O}-\mathrm{H}-\mathrm{O}$ and $\mathrm{C}=\mathrm{O}-\mathrm{H}-\mathrm{C}$ complexes, the triplet transition state, and the triplet radical pair for quinone $\mathbf{3}$, figures of relative energies are included in the supporting information.

Table 2 shows computed geometric parameters for the $\mathrm{S}_{0}$ complexes, the triplet transition states and triplet radical pairs for quinones 1 and 3. The calculated structures for the computed reaction path between the quinones and $2-\mathrm{PrOH}$ reveal that the structures for all steps for both aromatic ketones are very similar.

Table 2

Geometric parameters for the computed reaction structures

\begin{tabular}{|c|c|c|c|c|c|c|c|c|c|}
\hline \multirow[t]{3}{*}{ Quinone } & \multicolumn{8}{|c|}{ Interatomic distances $(\AA)^{\mathrm{a}}$} & \multirow[t]{3}{*}{ Transition state $\mathrm{C}=\mathrm{O}-\mathrm{H}\left({ }^{\circ}\right)$} \\
\hline & \multicolumn{3}{|c|}{ Reactant $\mathrm{S}_{0}$ complexes } & \multicolumn{3}{|c|}{ Triplet TS } & \multicolumn{2}{|c|}{ Triplet radical pair } & \\
\hline & $r 1 \mathbf{a}$ & $r \mathbf{1 b}$ & r1c & $r 2$ & $r 3$ & $r 4$ & r5 & $r 6$ & \\
\hline 1 & 2.566 & 2.102 & 2.661 & 2.206 & 1.244 & 1.442 & 1.875 & 2.103 & 111.6 \\
\hline 3 & 2.564 & 2.104 & 2.818 & 2.211 & 1.242 & 1.443 & 1.875 & 2.103 & 111.7 \\
\hline
\end{tabular}

a $r 1-r 6$ are depicted in Fig. 4. 


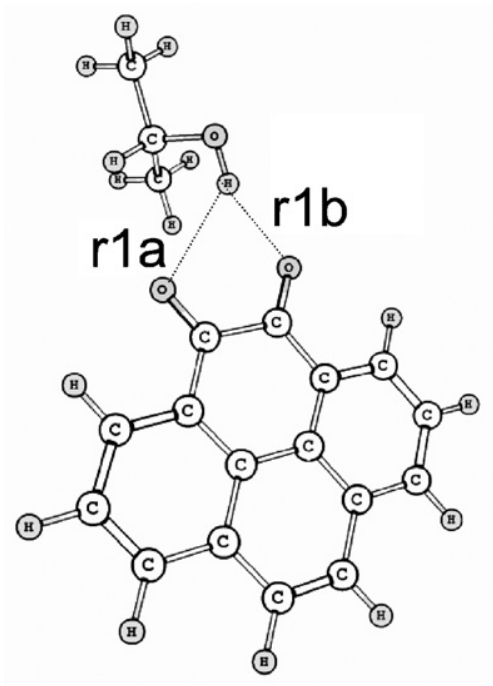

\section{$\mathrm{S}_{0} \mathrm{C}=\mathrm{O}---\mathrm{H}-\mathrm{O}$ complex}

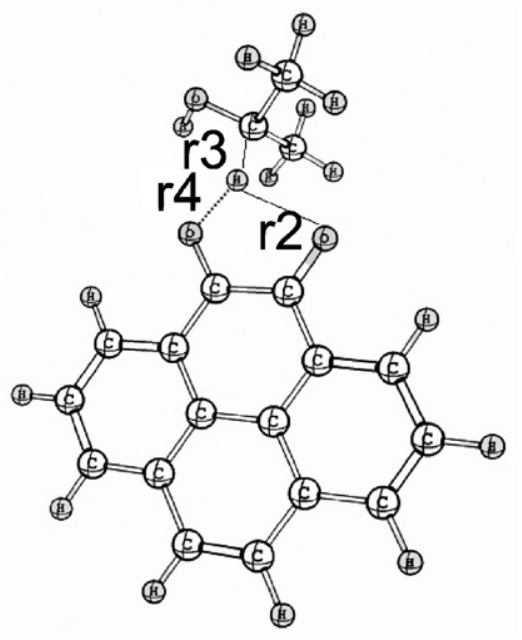

Transition state
$\mathrm{C}=\mathrm{O}---\mathrm{H}-\mathrm{C}$

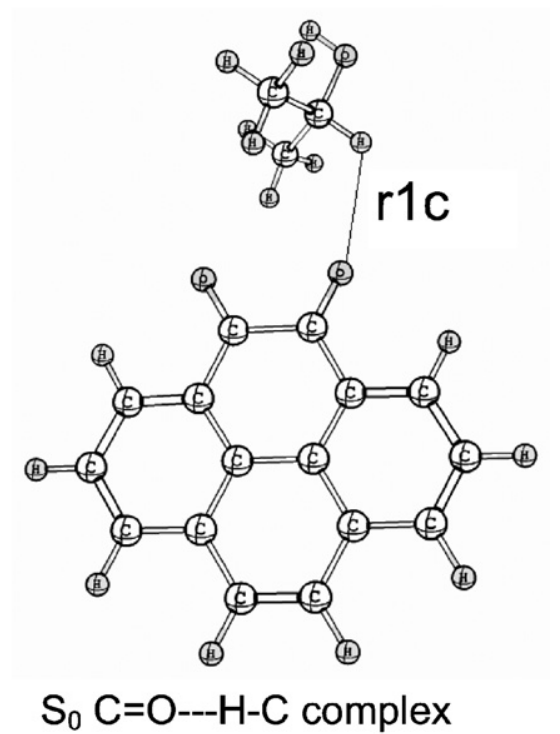

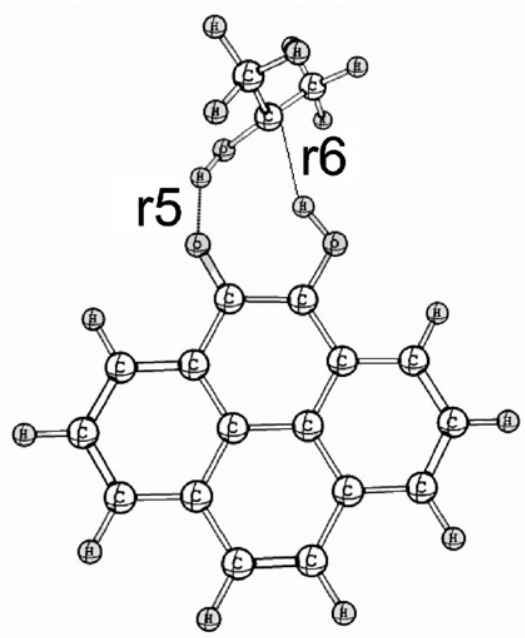

Triplet radical pair

Fig. 4. Calculated structures for hydrogen abstraction from 2-propanol by 3.

For the $\mathrm{S}_{0} \mathrm{C}=\mathrm{O}-\mathrm{H}-\mathrm{O}$ complex a hydrogen bond is formed to one of the carbonyl groups as revealed by the two interatomic distance values $r \mathbf{1 a}$ and $r \mathbf{1 b}$ (Table 2 ). In the case of the $\mathrm{S}_{0} \mathrm{C}=\mathrm{O}-\mathrm{H}-\mathrm{C}$ complex, no hydrogen bond is formed between the substrates, however the $\mathrm{C}-\mathrm{H}$ bond is closer to one of the $\mathrm{C}=\mathrm{O}$ groups than the other (Fig. 4). Further, it is also relevant to note that the triplet transi-

Table 3

UB3LYP/6-311+G**//UB3LYP/6-31G* energies for the reactions of the ortho-quinones $\mathbf{1}$ and $\mathbf{3}$ with 2-propanol

\begin{tabular}{lll}
\hline Energetic parameters & Quinone & \\
\cline { 2 - 3 } & $\mathbf{1}$ & $\mathbf{3}$ \\
\hline$T_{1}(\mathrm{kcal} / \mathrm{mol})$ & $52.9(49)^{\mathrm{a}}$ & $42.7(46)^{\mathrm{b}}$ \\
$\Delta G^{\neq}(\mathrm{kcal} / \mathrm{mol})^{\mathrm{c}}$ & 41.6 & 42.4 \\
$\Delta G_{\text {reaction }}(\mathrm{kcal} / \mathrm{mol})^{\mathrm{d}}$ & 25.8 & 25.2 \\
\hline
\end{tabular}

\footnotetext{
a Experimental value from Ref. [18].

b Experimental value from this work.

c Activation energy for the transition state in relation to the $\mathrm{S}_{0} \mathrm{C}=\mathrm{O}-\mathrm{H}-\mathrm{O}$ complex.

d The energy of the triplet radical pair relative to the $\mathrm{S}_{0} \mathrm{C}=\mathrm{O}-\mathrm{H}-\mathrm{O}$ complex.
}

tion states for both $\mathbf{1}$ and $\mathbf{3}$ show a preferential hydrogen transfer between the secondary alkoxy $\mathrm{C}-\mathrm{H}$ and one of the carbonyl groups. In other words, the hydrogen abstraction is asymmetric in relation to the two carbonyl groups, $r 2(2.206 \AA)>r 4(1.442 \AA$ ) (where $r 2$ and $r 4$ are the respective interatomic distances between an oxygen atom of the two carbonyl groups and the hydrogen atom being transferred, Table 2). This indicates a localized hydrogen abstraction with minimal vicinal carbonyl participation. These results are in good agreement with the similarities for quenching rates found for both ketones (Table 1 ). Minor differences in $k_{\mathrm{q}}$ are therefore due to subtle differences in the electronic nature of $\mathbf{1}$ and $\mathbf{3}$.

In a previous study [23] we noted very different geometries in the reaction paths for ortho-quinones with excited states of $n, \pi^{*}$ or $\pi, \pi^{*}$ character. Longer bond lengths between the ketone and phenol for the $\pi, \pi^{*}$ state were observed in comparison with the $n, \pi^{*}$ excited state ketones. The geometric values found in the present study are in good agreement with those found for the previous $\mathrm{n}, \pi^{*}$ quinones [23]. Therefore, by analogy between the present and previous computational results, the lowest excited state for both $\mathbf{1}$ and $\mathbf{3}$ would be $n, \pi^{*}$ in nature. This conclusion is further supported 
Table 4

Chelpg electron population of the ground state singlet complexes, triplet transition state and triplet radical pair for $\mathbf{1}$ and $\mathbf{3}$ reacting with 2-propanol in the gas phase

\begin{tabular}{|c|c|c|}
\hline \multirow[t]{2}{*}{ Mechanism step } & \multicolumn{2}{|c|}{ Chelpg electron population } \\
\hline & 1 & 3 \\
\hline Pure reactant & 102.0 & 120.0 \\
\hline Ground state $\mathrm{C}=\mathrm{O}-\mathrm{H}-\mathrm{O}$ complex $^{\mathrm{a}}$ & 101.9 & 119.9 \\
\hline Ground state $\mathrm{C}=\mathrm{O}-\mathrm{H}-\mathrm{C}$ complex $^{\mathrm{a}}$ & 101.9 & 119.9 \\
\hline Triplet transition state & 102.4 & 120.4 \\
\hline Triplet radical pair & 103.1 & 121.1 \\
\hline
\end{tabular}

a Chelpg charges for $\mathbf{1}$ and $\mathbf{3}$ without regarding the charge of 2-propanol. The Chelpg values which are less than those of the pure reactants are a consequence of the hydrogen bond between the reagents.

by analysis of the DFT frontier molecular orbitals where for both $\mathbf{1}$ and $\mathbf{3}$ the HOMO is $\mathrm{n}$ character and the SOMO of the triplet is $\pi$ character and essentially equivalent to the LUMO of the $S_{0}$ state (see supporting information).

Tables 3 and 4 detail the relative energies and charge data for the computed reaction paths. The theoretical value for the triplet energy of 1 is in good agreement with the experimental result [18]. Low temperature phosphorescence of $\mathbf{3}$ in methylcyclohexane revealed a band centered at $611 \mathrm{~nm}$ that was quenched by oxygen and was attributed to the triplet of 3 . This would correspond to an energy of $46 \mathrm{kcal} / \mathrm{mol}$. The calculated value for $\mathbf{3}$ is in good agreement with the experimental value. Small differences in the solvation of the quinones may be important and could therefore result in the difference between calculated and experimental triplet excited state energies.

The computed energies for the triplet transition state and triplet radical pair are relative to the respective $\mathrm{S}_{0} \mathrm{C}=\mathrm{O}-\mathrm{H}-\mathrm{O}$ complexes. As can be seen (Table 3 and supporting information), the activation energy for hydrogen abstraction by $\mathbf{1}(41.6 \mathrm{kcal} / \mathrm{mol})$ is $0.8 \mathrm{kcal} / \mathrm{mol}$ less than 3 ( $42.4 \mathrm{kcal} / \mathrm{mol})$. These results reveal that the first tripletexcited states for $\mathbf{1}$ and $\mathbf{3}$ have excess energy in relation to that required for the respective transition states. Therefore, it would be expected that hydrogen abstraction by the first triplet-excited state of $\mathbf{1}$ or $\mathbf{3}$ from 2-propanol be a barrierless process. In fact, Nicodem et al. in a previous study found no activation barrier for hydrogen abstraction from 2-propanol with the triplet 1 in $\mathrm{CCl}_{4}$ [20]. In this sense, the computed energy values are in agreement with the experimental results.

Table 4 shows the charge (Chelpg) flux in the computed reaction paths. As expected, there is no charge transfer in the $S_{0}$ complexes. But, in the triplet transition states one can see a large degree of charge transfer between 2-propanol and the ketones (almost $0.4 \mathrm{e})$. However, as seen from the geometric parameters detailed in Table 2 the transition states are early, the $\mathrm{C}-\mathrm{H}$ bond has been only marginally stretched. Therefore, the charge transfer, due to the electrophilicity of the excited state, and the triplet energies in excess of the energy required for the transition states are most likely the reasons for a barrierless hydrogen abstraction for the triplets $\mathbf{1}$ and $\mathbf{3}$.

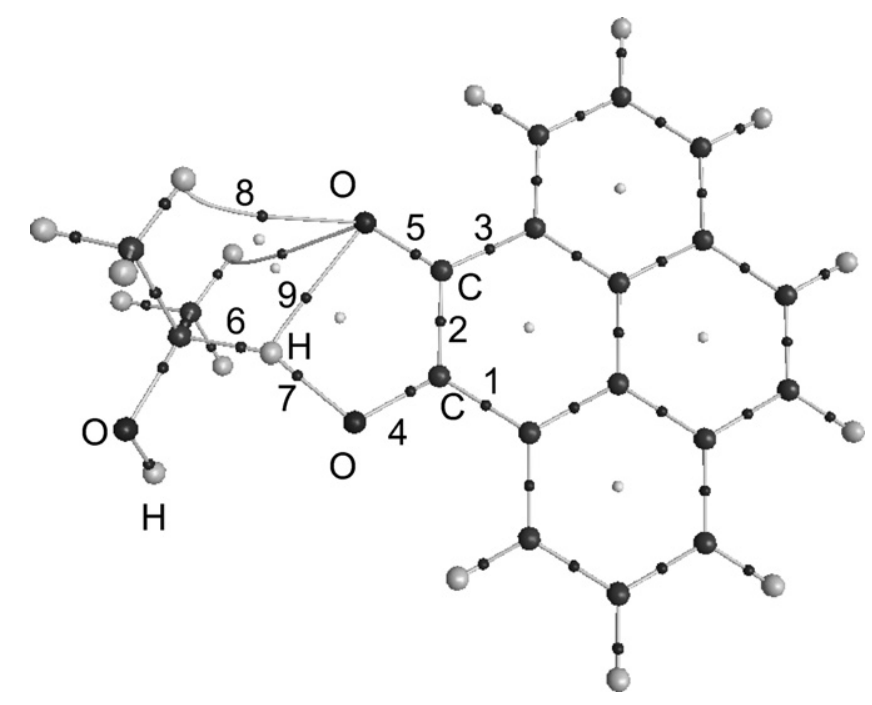

Fig. 5. AIM molecular graph of the triplet transition state for hydrogen abstraction from 2-propanol by 3.

A complementary study using AIM theory was performed in order to investigate the intermolecular interactions between the ortho-quinones and 2-propanol. In AIM theory, the interaction between two atoms is revealed by the presence of a charge density in the interconnecting space and this charge density is related to a bond critical point (BCP). Therefore, AIM can be used to infer the existence, or not, of a molecular interaction. The results in Table 5 and Fig. 5 reveal that the charge densities for the bond critical points (BCP) found are similar for both quinones in all structures of the computed reaction path. This behavior can be related to the similar magnitude of the transferred charge for the two ketones and is compatible with the experimental observation of similar reactivity with 2-propanol.

The BCP's 7, 8 and 9 can be used to infer the strength of the interactions between both reactants. The two quinones have almost no interaction with 2-propanol in the $\mathrm{S}_{0} \mathrm{C}=\mathrm{O}-\mathrm{H}$-C complex (BCP's 7, 8 and $9 \mathrm{ca}$. 0). In the triplet transition state, for both ketones, it can be seen that the most prominent intermolecular interaction is BCP 7 , which is 10 and 5 times greater than BCP's 8 and 9 , respectively. The $\mathrm{BCP} 9$ is related to the participation of the vicinal carbonyl group. As can be seen, the value for BCP 9 is very small and the interatomic distance $\mathrm{CO}-\mathrm{H}$ is greater than $2 \AA$. These results indicate that this secondary $\mathrm{CO}-\mathrm{H}$ interaction is very weak and is only found in the calculations as a result of the intense charge transfer at the transition state as no such interaction is observed in the $\mathrm{S}_{0}$ complexes [45].

Hydrogen abstraction from a substrate by triplet carbonyl species is observed to occur by a variety of mechanisms. The reactivity of a $n, \pi^{*}$ character triplet carbonyl has been compared to

Table 5

Charge density in some bond critical points for the carbonyl groups in the $\mathrm{S}_{0}$ complex, transition state and triplet radical pair for $\mathbf{1}$ and $\mathbf{3}$ reacting with 2-propanol

\begin{tabular}{|c|c|c|c|c|c|c|c|c|c|c|}
\hline \multirow[t]{2}{*}{ Compound } & \multirow[t]{2}{*}{ Mechanism step } & \multicolumn{9}{|c|}{ Charge density in critical point (a.u.) } \\
\hline & & 1 & 2 & 3 & 4 & 5 & 6 & 7 & 8 & 9 \\
\hline \multirow[t]{3}{*}{1} & Ground state $\mathrm{C}=\mathrm{O}-\mathrm{H}-\mathrm{C}$ complex & 0.269 & 0.247 & 0.269 & 0.400 & 0.400 & 0.284 & 0.006 & 0.004 & 0.005 \\
\hline & Transition state & 0.280 & 0.276 & 0.272 & 0.336 & 0.372 & 0.186 & 0.099 & 0.010 & 0.020 \\
\hline & Triplet radical pair & 0.293 & 0.291 & 0.275 & 0.306 & 0.367 & 0.023 & 0.326 & 0.028 & - \\
\hline \multirow[t]{3}{*}{3} & Ground state $\mathrm{C}=\mathrm{O}-\mathrm{H}-\mathrm{C}$ complex & 0.269 & 0.244 & 0.269 & 0.401 & 0.401 & 0.284 & 0.004 & 0.004 & 0.004 \\
\hline & Transition state & 0.280 & 0.273 & 0.272 & 0.335 & 0.373 & 0.186 & 0.098 & 0.010 & 0.019 \\
\hline & Triplet radical pair & 0.293 & 0.288 & 0.274 & 0.305 & 0.367 & 0.023 & 0.327 & 0.028 & - \\
\hline
\end{tabular}

a Critical points are depicted in Fig. 5. 
Table 6

$\mathrm{H}_{\text {tranferring }}$ atomic properties in transition state for different reactions ${ }^{\mathrm{a}}$

\begin{tabular}{llll}
\hline Reactive species & Volume $(\Omega)$ & Moment $(\Omega)$ & Charge $(\Omega)$ \\
\hline 1 & 20.1 & 0.041 & 0.274 \\
3 & 20.2 & 0.046 & 0.274 \\
$t$-Butoxyl radical & 19.9 & 0.037 & 0.272 \\
Methyl radical & 29.1 & 0.0048 & 0.117 \\
\hline
\end{tabular}

a Atomic properties are obtained by integrating over the atomic basin $(\Omega)$, which is the space the atom occupies and is dimensionless in the AIM theory.

that of $t$-butoxyl radical for years [46]. However, in the case of phenolic hydrogen abstraction, reaction does not occur by a simple abstraction of a hydrogen atom. Leigh et al. [47] have shown for a series of aromatic ketone triplets that phenolic hydrogen abstraction reactions are consistent with a continuum of two different mechanisms: (1) a simple electron transfer which applies to the $\mathrm{n}, \pi^{*}$ triplet ketones and those $\pi, \pi^{*}$ triplets with low reduction potential and (2) a proton-coupled electron transfer (PCET) mechanism involving the intermediacy of a hydrogen-bonded exciplex for $\pi, \pi^{*}$ triplets that are less easily reduced. Further, de Lucas et al. [23] showed that $n, \pi^{*}$ triplet ketones may also react via a PCET mechanism. In a recent paper, Singh et al. [48] studied the mechanistic aspects of hydrogen abstraction for phenolic antioxidants using AIM theory. The reaction mechanism was evaluated for substituted phenols reacting with hydroperoxyl radical in terms of two extremes as proposed by Mayer et al. [49] a pure hydrogen atom transfer (HAT) or a PCET. The analysis of the transferring $\mathrm{H}$ atom showed that hydrogen abstraction by the hydroperoxyl radical follows a PCET mechanism for reactions with phenols. Our previous results indicated that the reaction of the triplet state of aromatic ketones with phenol could occur either by an electron transfer or a PCET like mechanism [23].

Therefore, in order to further evaluate the nature of the quinone reactivity, the transferring $\mathrm{H}$ atom $\left(\mathrm{H}_{\text {transferring }}\right)$ was evaluated by comparing its atomic properties with two typical radical reactions: the electrophilic $t$-butoxyl radical reacting with 2-propanol and methyl radical reacting with the same alcohol. Table 6 shows the $\mathrm{H}_{\text {transferring }}$ atomic properties in the respective transition states. The $H_{\text {transferring }}$ atom volume is very similar for species 1,3 and the $t$-butoxyl radical, with values of around 20 a.u. When the reaction has a classical HAT mechanism such as in the case of the methyl radical/2-propanol pair, the $\mathrm{H}_{\text {transferring }}$ atom volume is $50 \%$ larger. The $\mathrm{H}_{\text {transferring }}$ charges also show distinct character. The charge of the $\mathrm{H}_{\text {transferring }}$ atom for the methyl radical/2-propanol pair is only $40 \%$ of that found for the reactions of 1,3 and $t$-butoxyl radical. Finally, as the atomic moment $M_{1}$ is sensitive to the electron density far from the nucleus, one can see that for a HAT mechanism the $\mathrm{H}_{\text {transferring }}$ has a more spherical charge distribution (lower value) when compared to the values for the reactions of 1, 3 and $t$-butoxyl radical. These results, along with those for transferred charge in Table 4 indicate that hydrogen abstraction reactions for $\mathbf{1}$ and $\mathbf{3}$ follow a PCET like mechanism, and not a HAT mechanism. This is consistent with the highly accentuated electrophilic nature for the excited state triplets of $\mathbf{1}$ and $\mathbf{3}$. Further, the quenching rate constants for the triplet excited states of $\mathbf{1}$ and $\mathbf{3}$ are one or two orders of magnitude larger than for other $n, \pi^{*}$ mono and diketones (1,2-napthoquinone[21] = 7.6 $\times 10^{6}$; benzophenone[46] $=1.6 \times 10^{6}$; biacetyl[46] $=1.0 \times 10^{4} ; \quad$ 1,1,4,4-tetramethyl-1,4-dihydro-2,3napthalendione $[50]=2.6 \times 10^{7}, 1$-acenaphthenone[16] $=1.3 \times 10^{5}$ and acenapthenequinone[16] $=6.2 \times 10^{5} \mathrm{~L} \mathrm{~mol}^{-1} \mathrm{~s}^{-1}$ ). In fact, the excited triplet states of $\mathbf{1}$ and $\mathbf{3}$ have, to the best of our knowledge, the largest rate constants for hydrogen abstraction from 2-PrOH that can be found in the literature.

\section{Conclusion}

The triplet state of $\mathbf{3}$ was detected by laser flash photolysis experiments. The hydrogen abstraction from 2-propanol as hydrogen donor in chlorobenzene, revealed $\mathbf{3}$ to be more reactive than $\mathbf{1}$, but their reactivities are comparable and dependent upon the solvent polarity. The results from the DFT and AIM calculations: (a) quinone triplet excited state energies greater than the respective energies for the hydrogen abstraction transition states, (b) early transition state geometries, (c) atomic charges that reveal substantial charge transfer in the transition states, (d) a small atomic volume, and (e) a less spherical charge distribution of the atomic moment for the hydrogen abstraction by $\mathbf{1}$ and $\mathbf{3}$ from 2-propanol are best interpreted as a PCET like mechanism. The excited state triplets of quinones $\mathbf{1}$ and $\mathbf{3}$ have the largest rate constant values for hydrogen abstraction from 2-PrOH in comparison with data from the literature.

\section{Acknowledgments}

We thank Prof. J.C. Scaiano for the use of the LFP equipment and C.N. Sanrame for assistance with the LFP experiments undertaken at the University of Ottawa, Canada. JCN-F and SJG thank the Conselho Nacional de Desenvolvimento Científico e Tecnológico for fellowships.

\section{Appendix A. Supplementary data}

Supplementary data associated with this article can be found, in the online version, at doi:10.1016/j.jphotochem.2008.08.014.

\section{References}

[1] J.R. Burie, A. Boussac, C. Boullais, G. Berger, T. Mattioli, C. Mioskowski, E. Nabedryk, J. Breton, FTIR spectroscopy of UV-generated quinone radicals: evidence for an intramolecular hydrogen atom transfer in ubiquinone, naphthoquinone, and plastoquinone, J. Phys. Chem. 99 (1995) 4059-4070.

[2] V. Plalniappan, P.C. Martin, V. Chynwar, H.A. Frank, D.F. Bocian, Comprehensive resonance Raman study of photosynthetic reaction centers from Rhodobacter sphaeroides. Implications for pigment structure and pigment-protein interactions, J. Am. Chem. Soc. 115 (1993) 12035-12049.

[3] C. Kirmaier, D. Holten, Primary photochemistry of reaction centers from the photosynthetic purple bacteria, Photosynth. Res. 13 (1987) 225-260.

[4] H.H. Robinson, A.R. Crofts, Kinetics of the oxidation-reduction reactions of the photosystem II quinone acceptor complex, and the pathway for deactivation, FEBS Lett. 153 (1983) 221-226.

[5] J.M. Bruce, in: S. Patai (Ed.), The Chemistry of the Quinonoid Compounds, Wiley-Interscience, New York, 1974, p. 465.

[6] M.B. Rubin, Recent photochemistry of alpha-diketones, Top. Curr. Chem. 129 (1985) $1-56$

[7] M.B. Rubin, P. Zwikowits, Photochemical reactions of diketones. II. 1a,b The 1,2 addition of substituted toluenes to 9,10-phenanthrenequinone, J. Org. Chem. 29 (1964) 2362-2368.

[8] P.A. Carapellucci, H.P. Wolf, K. Weiss, Photoreduction of 9,10phenanthrenequinone, J. Am. Chem. Soc. 91 (1969) 4635-4639.

[9] T. Maruyama, T. Otsuki, Y. Naruta, Photochemical reaction of 9,10phenanthrenequinone with hydrogen donors-behavior of radicals in solution as studied by CIDNP, Bull. Chem. Soc. Jpn. 49 (1976) 791-795.

[10] G.G. Lazarev, Y.S. Lebedev, A.I. Prokofev, R.R. Rakhimov, Hydrogen and electrontransfer in the photo-reduction reaction of quinones, Chem. Phys. Lett. 95 (1983) 262-265.

[11] A. Takuwa, O. Soga, K. Maruyama, The Photochemical reaction of 1,2naphthoquinone with hydrogen donor-an explanation of the coupling sites of alkyl and acyl radicals to 1,2-naphthosemiquinone Radical, J. Chem. Soc. Perkin Trans. 2 (3) (1985) 409-411.

[12] C. Tintel, J. Terheijden, J. Lugtenburg, J. Cornelisse, Photoreduction and photoaddition reactions of pyrenediones, Tetrahedron Lett. 28 (1987) 2057-2060.

[13] X.H. Ci, R.S. Silva, J.L. Goodman, D.E. Nicodem, D.G. Whitten, A reversible photoredox reaction-electron-transfer photoreduction of $\beta$-lapachone by triethylamine, J. Am. Chem. Soc. 110 (1988) 8548-8550.

[14] X. Ci, R.S. Silva, D.E. Nicodem, D.G. Whitten, Electron and hydrogen-atom transfer mechanism for the photoreduction of ortho-quinones-visible light induced photoreaction of beta-lapachone with amines, alcohols and amino-alcohols, J. Am. Chem. Soc. 111 (1989) 1337-1343. 
[15] R.S. Becker, L.V. Natarajan, Comprehensive absorption, photophysical/chemical and theoretical study of 2-5-ring aromatic hydrogen diones, J. Phys. Chem. 97 (1993) 344-349.

[16] N.C. Lucas, J.C. Netto-Ferreira, Laser flash photolysis study of the hydrogen abstraction properties of acenaphthequinone and 1-acenaphthenone, J. Photochem. Photobiol. A: Chem. 116 (1998) 203-208.

[17] M. Barra, E.D. Harder, J.P. Balfe, Influence of solvent polarity on the photoreactivity of 2-4-ring aromatic o-quinones, J. Chem. Soc. Perkin Trans. 2 (1999) 1439-1441.

[18] R.S. Silva, D.E. Nicodem, Solvent and temperature effects on the phosphorescence of 9,10-phenanthrenequinone in fluid solution, J. Photochem. Photobiol. A: Chem. 162 (2004) 231-238.

[19] A.C. Serra, N.C. Lucas, J.C. Netto-Ferreira, Laser flash photolysis study of the phenolic hydrogen abstraction by 1,2-aceanthrylenedione triplet, J. Braz. Chem. Soc. 15 (2004) 481-486

[20] D.E. Nicodem, R.S. Silva, D.M. Togashi, M.F.V. Cunha, Solvent effects on the quenching of the equilibrating $n, \pi^{*}$ and $\pi, \pi^{*}$ triplet sate of 9,10 phenanthrenequinone by 2-propanol, J. Photochem. Photobiol. A: Chem. 175 (2005) 154-158

[21] Y. Harada, S. Watanabe, T. Suzuki, T. Ichimura, Photochemical reaction dynamics of 9,10-phenanthrenequinone and 1,2-naphthoquinone with hydrogen donors in solution, J. Photochem. Photobiol. A: Chem. 179 (2005) 161-167.

[22] Y. Pan, Y. Fu, S. Liu, H. Yu, Y. Gao, Q. Guo, S. Yu, Studies on photoinduced H-atom and electron transfer reaction of $o$-naphthoquinones by laser flash photolysis J. Phys. Chem. A 110 (2006) 7316-7322.

[23] N.C. Lucas, R.J. Corrêa, A.C. Albuquerque, C.L. Firme, S.J. Garden, A.R. Bertoti, J.C. Netto-Ferreira, Laser flash photolysis of 1,2-diketopyracene and a theoretical study of the phenolic hydrogen abstraction by the triplet of cyclic alpha-diketones, J. Phys. Chem. A 111 (2007) 1117-1122.

[24] J.-P. Malval, C. Dietlin, X. Allonas, J.-P. Fouassier, Sterically tuned photoreactivity of an aromatic a-diketone family, J. Photochem. Photobiol. A: Chem. 192 (2007) 66-73.

[25] P.J. Wagner, Chemistry of excited triplet organic carbonyl compounds, Top. Curr. Chem. 66 (1976) 1-52.

[26] P.J. Wagner, B.-S. Park, Photoinduced hydrogen atom abstraction by carbonyl compounds, Org. Photochem. 11 (1991) 227-366.

[27] P.J. Wagner, A.E. Kemppainen, H.N. Schott, Effects of ring substituents on the Type II photoreactions of phenyl ketones. How interactions between nearby excited triplets affect chemical reactivity, J. Am. Chem. Soc. 95 (1973) 5604-5614.

[28] K. Maruyama, K. Ono, J. Osugi, Photochemical reaction of alpha-diketones, Bull. Chem. Soc. Jpn. 45 (1972) 847-851.

[29] N.C. Lucas, M.T. Silva, C. Gege, J.C. Netto-Ferreira, Steady state and laser flash photolysis of acenaphthenequinone in the presence of olefins, J. Chem. Soc. Perkin Trans. 2 (1999) 2795-2801

[30] J.-H. Ho, T.-I. Ho, T.H. Chen, Y.L. Chow, Efficient photocycloaddition of phenanthrenequinones with simple olefins, J. Photochem. Photobiol. A: Chem. 138 (2001) 111-122.

[31] K.G. Bendinskas, A. Harsch, R. Wilson, R.W. Midden, Sequence-specific photomodification of DNA by an oligonucleotide-phenanthrodihydrodioxin conjugate, Bioconjugate Chem. 9 (1998) 555-563.
[32] E.T. Mack, A.B. Carle, J.T.M. Liang, W. Coyle, R.M. Wilson, Thermal and photochemistry of pyrene dihydrodioxin (PDHD) and Its radical cation: a photoactivated masking group for ortho-quinones, J. Am. Chem. Soc. 126 (2004) 15324-15325.

[33] R.L. Funk, E.R.R. Young, A practical synthesis of pyrene-4,5-dione, J. Org. Chem. 63 (1998) 9995-9996.

[34] Z. Wang, V. Enkelmann, F. Negri, K. Müellen, Rational design of helical columnar packing in single crystals, Angew. Chem. Int. Ed. Engl. 43 (2004) 1972.

[35] R. Fletcher, Practical Methods of Optimization, Wiley, New York, 1980.

[36] M.J. Frisch, et al., Gaussian 98, Revision A 7, Gaussian, Inc., Pittsburgh, PA, 1998.

[37] R.F.W. Bader, A quantum theory of molecular structure and its applications, Chem. Rev. 91 (1991) 893-928.

[38] R.F.W. Bader, Atoms in molecules, Acc. Chem. Res. 18 (1985) 9-15.

[39] S.L. Murov, I. Carmichael, G.L. Hug, Handbook of Photochemistry, Marcel Dekler, Inc., New York, 1993.

[40] J.C. Scaiano, Intermolecular photoreductions of ketones, J. Photochem. 2 $(1973 / 1974) 81$

[41] J.C. Scaiano, Solvent effects in the photochemistry of xanthone, J. Am. Chem. Soc. 102 (1980) 7747-7753.

[42] J. Perez-Prieto, S.-E. Stiriba, F. Boscá, A. Lahoz, L.R. Domingo, F. Mourabit, S. Monti, M.A. Miranda, Geometrical effects on the intramolecular quenching of $\pi, \pi^{*}$ aromatic ketones by phenols and indoles, J. Org. Chem. 69 (2004) 8618-8625.

[43] J. Perez-Prieto, F. Boscá, R.E. Galian, A. Lahoz, L.R. Domingo, M.A. Miranda, Photoreaction between 2-benzoythiophene and phenol or indole, J. Org. Chem. 68 (2003) 5104-5113.

[44] S. Abad, F. Bosca, L.R. Domingo, S. Gil, U. Pischel, M.A. Miranda, Triplet reactivity and regio-/stereoselectivity in the macrocyclization of diastereomeric ketoprofen-quencher conjugates via remote hydrogen abstractions, J. Am. Chem. Soc. 129 (2007) 7407-7420.

[45] U. Koch, P.L.A. Popelier, Characterization of $\mathrm{C}-\mathrm{H}-\mathrm{O}$ hydrogen bonds on the basis of the charge density, J. Phys. Chem. 99 (1995) 9747-9754

[46] N.J. Turro, Modern Molecular Photochemistry, University Science Books, Mill Valley, California, 1991.

[47] W.J. Leigh, E.C. Lathioor, M.J.S. Pierre, Photoinduced hydrogen abstraction from phenols by aromatic ketones. A new mechanism for hydrogen abstraction by carbonyl $n, \pi^{*}$ and $\pi, \pi^{*}$ triplets, J. Am. Chem. Soc. 118 (1996) 1233912348.

[48] N. Singh, P.J. O’Malley, P.L.A. Popelier, Mechanistic aspects of hydrogen abstraction for phenolic antioxidants. Electronic structure and topological electron density analysis, Phys. Chem. Chem. Phys. 7 (2005) 614-619.

[49] J.M. Mayer, D.A. Hrovat, J.L. Thomas, W.T. Borden, Proton-coupled electron transfer versus hydrogen atom transfer in benzyl/toluene, methoxyl/methanol, and phenoxyl/phenol self-exchange reactions, J. Am. Chem. Soc. 124 (2002) 11142-11147.

[50] J.C. Scaiano, V. Wintgens, J.C. Netto-Ferreira, Importance of neighboring group participation in the remarkably rapid photoreduction of 1,1,4,4-tetramethyl1,4-dihydro-2,3-naphthalenedione, Photochem. Photobiol. 50 (1989) 707710 . 